\title{
Social disability of Brazilian mood disorder patients
}

A.M. Tucci' ${ }^{1}$,

F. Kerr-Corrêa ${ }^{2}$ and R.S. Dias ${ }^{2}$

\author{
'Departamento de Psicobiologia, Universidade Federal de São Paulo, \\ Escola Paulista de Medicina, São Paulo, SP, Brasil \\ ${ }^{2}$ Departamento de Neurobiologia e Psiquiatria, Faculdade de Medicina, \\ Universidade Estadual Paulista, Botucatu, SP, Brasil
}

\section{Correspondence}

A.M. Tucci

Rua Agenor Nogueira, 952

Jd. Bom Pastor

18603-560 Botucatu, SP

Brasil

E-mail: adritucci@uol.com.br

Research supported by FAPESP (No. 97/06382-8).

Received August 13, 2003 Accepted August 5, 2004

\begin{abstract}
Mood disorders cause many social problems, often involving family relationships. Few studies are available in the literature comparing patients with bipolar, unipolar, dysthymic, and double depressive disorders concerning these aspects. In the present study, demographic and disease data were collected using a specifically prepared questionnaire. Social adjustment was assessed using the Disability Adjustment Scale and family relationships were evaluated using the Global Assessment of Relational Functioning Scale. One hundred patients under treatment for at least 6 months were evaluated at the Psychiatric Outpatient Clinic of the Botucatu School of Medicine, UNESP. Most patients were women $(82 \%)$ more than $50(49 \%)$ years old with at least two years of follow-up, with little schooling (62\% had less than 4 years), and of low socioeconomic level. Logistic regression analysis showed that a diagnosis of unipolar disorder $(\mathrm{P}=0.003, \mathrm{OR}=0.075$, $\mathrm{CI}=0.014-0.403)$ and dysthymia $(\mathrm{P}=0.001, \mathrm{OR}=0.040, \mathrm{CI}=0.006-$ $0.275)$ as well as family relationships $(\mathrm{P}=0.002, \mathrm{OR}=0.953, \mathrm{CI}=$ 0914-0.992) played a significant role in social adjustment. Unipolar and dysthymic patients presented better social adjustment than bipolar and double depressive patients $(\mathrm{P}<0.001)$, results that were not due to social class. These patients, treated at a teaching hospital, may represent the severest mood disorder cases. Evaluations were made knowing the diagnosis of the patients, which might also have influenced some of the results. Social disabilities among mood disorder patients are very frequent and intensive.
\end{abstract}

Key words

- Mood disorders

- Depression

- Bipolar

- Social adjustment

- Unipolar

\section{Introduction}

Various studies in different countries have demonstrated the difficulty of mood disorder patients to readapt to the environment $(1,2)$. The risk of unemployment is twice as high for these patients than for the general population and, when they are employed, they have low output $(3,4)$. It is known that the interaction between family and patient is an important trigger for mood disorders and that these relationships are normally rife with hostility and lack of trust and acceptance (5).

In Brazil, few studies have investigated the medical, social, and demographic characteristics of mood disorder patients. A better understanding of the present situation is needed, in order to permit the planning of 
mental health programs which will be more consistent with the real necessities of the sufferers and their families.

The goal of the present study was to approach these issues by characterizing and evaluating patients diagnosed, by the International Classification of Disease, Brazilian version-10 (ICD-10) (6), with mood disorders - bipolar and unipolar disorders, dysthymia, and double depression (patients who have a dysthymic disorder and a concurrent major depression) undergoing outpatient treatment at a teaching hospital (HC-UNESP) in Botucatu, São Paulo.

\section{Patients and Methods}

\section{Disability Adjustment Scale (7)}

Disability was determined by the level of impairment of patient behavior and by patient performance in social relations using a translated version of sections 1,2 , and 5 of Chaves et al. (8). Section 1 is composed of 6 scores ranging from 0 to 5 . However, no patient received an evaluation of 0 or 5 and therefore the subjects were divided into four groups, with scores from 1 to 4 . The Portuguese version of the Disability Adjustment Scale (DAS) has shown good reliability among different evaluators (9).

The sum of the scores on this scale was calculated to indicate Global Social Adjustment (GSA). On this scale the higher the average, the worse the adjustment of the patient.

\section{Global Assessment of Relational Functioning Scale (10)}

The Global Assessment of Relational Functioning (GARF) Scale is used to evaluate family performance, from satisfactory relationships with few conflicts to standards of dysfunctional relationships with little communication and many conflicts. GARF scores are divided into four categories: 81 to 100 - good family performance, with good, warm, close relationships, and few large conflicts which, when present, are resolved with good communication and negotiation; 61 to 80 functioning of family relationship somewhat unsatisfactory, some conflicts remain unresolved but without disrupting family function, a range of feeling is expressed, and there are good and lovely relations and respect; 41 to 60 - family with occasional moments of satisfaction, but there is a predominance of unsatisfactory relationships and unviable communication with unresolved conflicts; 21 to 40 - family clearly dysfunctional, with the presence of tyranny and power or strong negligence, good contact is rare and conflicts remain unresolved.

The results of the GARF scale were grouped into two categories for regression analysis according to the family relationship score. Patients with scores ranging from 61 to 100 were included in the good and reasonable family relationship group, whereas those with scores ranging from 0 to 60 were considered to be patients with poor to very dysfunctional family relationships.

\section{Procedure for the interview and scale application}

All HC-UNESP mood disorder outpatients were identified and invited (when necessary) to participate in the interview and testing after signing a term of informed consent. The local Ethics Committee approved the project. Psychiatrists at the outpatient clinic had already diagnosed all participating patients, who were already under supervision.

The first author was trained by the second author regarding the DAS and GARF questionnaires. All interviews and scale assessments were conducted face to face by the first author. The interviewer was supervised throughout the year to answer any questions that arose, as a control for interview bias and to address issues regarding the sensitivity of some of the questions. 


\section{Statistical analysis}

Data were analyzed using the SPSS software version 7.0 (11). Frequency distributions were calculated for all diagnostic categories and other variables. Comparisons between groups were based on the chi-square or exact Fisher test $(12,13)$ for categorical variables and on analysis of variance for numerical variables. All alternative hypotheses formulated were submitted to the twotailed test and the results tabulated.

When the result of the overall $\mathrm{F}$ statistic was significant we used analysis of variance followed by the post hoc test to compare the mean values between different groups for each of the DAS sections: personal care, inactivity, slowness, social isolation, participation, conjugal mood relationship, conjugal sexual relationship, sexual contacts, social contacts, performance at work, interest in work, obtaining information, and behav- ior in emergencies. In addition, the relationship between GSA data and all other variables for which an overall significant association was found was evaluated using logistic regression analysis of GSA (12). The GSA was chosen as the dependent variable. GSA results were grouped into two categories for regression analysis - good and reasonable, and poor and severe. The GSA logit was the best numeric results against the worst results in the GSA.

\section{Results}

\section{Socioeconomic and demographic data}

The four diagnostic groups: bipolar, unipolar, dysthymia, and double depression did not differ significantly in age, sex, occupation, marital status, family income, or schooling. The sociodemographic data are shown in Table 1. The main socioeconomic and

Table 1. Sociodemographic data of the mood disorder patients.

\begin{tabular}{|c|c|c|c|c|c|c|c|c|}
\hline \multirow[t]{2}{*}{ Variables } & \multicolumn{2}{|c|}{$\begin{array}{l}\text { Bipolar } \\
(N=29)\end{array}$} & \multicolumn{2}{|c|}{$\begin{array}{l}\text { Unipolar } \\
(\mathrm{N}=35)\end{array}$} & \multicolumn{2}{|c|}{$\begin{array}{l}\text { Dysthymia } \\
(N=23)\end{array}$} & \multicolumn{2}{|c|}{$\begin{array}{c}\text { Double depression } \\
\qquad(\mathrm{N}=13)\end{array}$} \\
\hline & $\mathrm{N}$ & $\%$ & $\mathrm{~N}$ & $\%$ & $\mathrm{~N}$ & $\%$ & $\mathrm{~N}$ & $\%$ \\
\hline \multicolumn{9}{|l|}{ Age (years) } \\
\hline Up to 30 & 3 & 10.3 & 3 & 8.5 & 1 & 4.3 & 1 & 7.6 \\
\hline 30 to 50 & 15 & 51.7 & 10 & 28.5 & 12 & 52.1 & 6 & 46.1 \\
\hline Over 50 & 11 & 37.9 & 22 & 62.8 & 10 & 43.4 & 6 & 46.1 \\
\hline \multicolumn{9}{|l|}{ Gender } \\
\hline Male & 9 & 31.0 & 3 & 8.5 & 4 & 17.3 & 2 & 15.3 \\
\hline Female & 20 & 68.9 & 32 & 91.4 & 19 & 82.6 & 11 & 84.6 \\
\hline \multicolumn{9}{|l|}{ Marital status } \\
\hline Single & 5 & 17.2 & 4 & 11.4 & 1 & 4.3 & 1 & 7.7 \\
\hline Married/living together & 16 & 55.2 & 24 & 68.6 & 16 & 69.6 & 8 & 61.5 \\
\hline Widower & 4 & 13.8 & 5 & 14.3 & 1 & 4.3 & 1 & 7.7 \\
\hline Separate/divorced & 4 & 13.8 & 2 & 5.7 & 5 & 21.7 & 3 & 23.1 \\
\hline \multicolumn{9}{|l|}{ Schooling } \\
\hline Primary school & 15 & 51.7 & 25 & 71.4 & 16 & 69.5 & 8 & 61.5 \\
\hline Secondary school & 11 & 37.9 & 5 & 14.2 & 5 & 21.7 & 5 & 38.4 \\
\hline >Secondary school & 3 & 10.3 & 5 & 14.2 & 2 & 8.7 & 0 & - \\
\hline \multicolumn{9}{|l|}{ Occupation } \\
\hline Housewife & 9 & 31.0 & 14 & 40.0 & 7 & 30.4 & 6 & 46.1 \\
\hline Employed & 11 & 38.0 & 16 & 45.7 & 11 & 47.8 & 5 & 38.5 \\
\hline Retired & 5 & 17.2 & 5 & 14.3 & 5 & 21.7 & 1 & 7.7 \\
\hline Unemployed & 4 & 13.7 & 0 & 0 & 0 & 0 & 1 & 7.7 \\
\hline
\end{tabular}

There were statistical differences between patient groups $\left(\chi^{2}\right.$ test). 
demographic characteristics of most patients in the four groups were: age over 30 , female sex, employed, married, with monthly family income below US\$200, and less than 8 years of education.

\section{Clinical history and disease outcome}

There was no statistically significant difference between groups for age at onset of the disease, number of depression episodes, presence of triggering factors, and mental illness in the family.

The groups differed significantly in number of hospitalizations during their lives $\left(\chi^{2}\right.$ $=25.6 ; \mathrm{P}=0.00001)$, with the bipolar patients showing the highest number of hospitalizations during their lives and the dysthymic, the lowest. Most patients with the different types of depression had never been hospitalized. Age at first hospitalization was after 40, except for the bipolar group, for which it was between 31 and 40 .
Another significantly different variable in all groups was number of work days lost per year due to the disease $\left(\chi^{2}=10.81 ; \mathrm{P}=\right.$ $0.013)$, with bipolar patients having lost the largest number of workdays. The bipolar patients also received significantly more preventive drug treatments $\left(\chi^{2}=13.28 ; \mathrm{P}=\right.$ $0.004)$.

\section{Family relationship characteristics}

Table 2 shows the results of evaluation of family relationships. No statistically significant differences regarding family relationships were found between groups.

\section{Social adjustment}

GSA differed significantly between groups $(\mathrm{P}<0.001)$. Bipolar and double depression patients showed the worst results for social adjustment (Table 3).

Table 4 shows the result of analysis of

Table 2. Patient scores on the Global Assessment of Relational Functioning Scale.

\begin{tabular}{|c|c|c|c|c|c|c|c|c|}
\hline \multirow[t]{2}{*}{ Disorders } & \multicolumn{2}{|c|}{ Good } & \multicolumn{2}{|c|}{ Regular } & \multicolumn{2}{|c|}{ Poor } & \multicolumn{2}{|c|}{ Severe } \\
\hline & $\mathrm{N}$ & $\%$ & $\mathrm{~N}$ & $\%$ & $\mathrm{~N}$ & $\%$ & $\mathrm{~N}$ & $\%$ \\
\hline Bipolar & 2 & 6.9 & 15 & 51.7 & 9 & 31.1 & 3 & 10.3 \\
\hline Unipolar & 12 & 34.3 & 16 & 45.7 & 3 & 8.6 & 4 & 11.4 \\
\hline Dysthymia & 3 & 13.1 & 11 & 47.8 & 5 & 21.7 & 4 & 17.4 \\
\hline Double depression & 2 & 15.4 & 4 & 30.8 & 4 & 30.8 & 3 & 23.0 \\
\hline
\end{tabular}

No statistically significant differences were found between patient groups ( $\chi^{2}$ test).

Table 3. Scores for mood disorder patient on the Disability Adjustment Scale.

\begin{tabular}{|c|c|c|c|c|c|c|c|c|}
\hline \multirow[t]{2}{*}{ Disorders } & \multicolumn{2}{|c|}{ Good } & \multicolumn{2}{|c|}{ Regular } & \multicolumn{2}{|c|}{ Poor } & \multicolumn{2}{|c|}{ Severe } \\
\hline & $\mathrm{N}$ & $\%$ & $\mathrm{~N}$ & $\%$ & $\mathrm{~N}$ & $\%$ & $\mathrm{~N}$ & $\%$ \\
\hline Bipolar & 2 & $6.9^{*}$ & 11 & 37.9 & 10 & $34.4^{*}$ & 6 & 20.6 \\
\hline Unipolar & 10 & 28.5 & 19 & $54.2^{+}$ & 3 & 8.5 & 3 & $8.5^{*}$ \\
\hline Dysthymia & 4 & 17.3 & 16 & $69.5^{*}$ & 3 & 13.0 & 0 & $0^{*}$ \\
\hline Double depression & 3 & 23.0 & 1 & $7.6^{*}$ & 7 & $53.8^{*}$ & 2 & 15.3 \\
\hline
\end{tabular}

${ }^{*} \mathrm{P}<0.05$ compared to the other disorders $\left(\chi^{2}\right.$ test). ${ }^{+} \mathrm{P}=0.01$ compared to bipolar and double depression $\left(\chi^{2}\right.$ test) 
variance of the data regarding the DAS sections, with identification of social adjustment in different areas. In general, the sexual role for both married and unmarried people was the item with the worst results. The subitems of the DAS with a significant difference between the four groups were: personal care $(\mathrm{P}=0.012$, d.f. $=3.99, \mathrm{~F}=3.876)$, social isolation $(\mathrm{P}=0.035$, d.f. $=3.99, \mathrm{~F}=2.982)$, domestic participation $(\mathrm{P}=0.001$, d.f. $=$ $3.99, \mathrm{~F}=6.376)$, and work performance $(\mathrm{P}=$ 0.023 , d.f. $=3.99, \mathrm{~F}=3.572)$. The post hoc test showed that bipolar and double depression patients were significantly more impaired than unipolar and dysthymic patients regarding all items (personal care, social isolation, participation at home, and performance at work). There was no significant difference between bipolar and double de- pression patients in any of these items.

\section{Variables associated with social adjustment}

Table 5 shows the data regarding logistic regression analysis. Due to the small number of patients in this study, the confidence interval of some variables was relatively large.

The diagnosis and family relationship variables reached significant levels in regression analysis.

The logit of the chosen diagnosis was the result obtained for patients with double depression against each of the other diagnoses. The odds ratio between double depression and bipolar disorder was not statistically different from that for social adjustment.

The odds ratio between double depression and unipolar disorder was 0.075 , indi-

Table 4. Patient scores on the individual sections of the Disability Adjustment Scale (DAS).

\begin{tabular}{lcrrr}
\hline DAS section & Bipolar & Unipolar & \multicolumn{1}{c}{ Dysthymia } & Double \\
\hline 1.1 Personal care* & $0.34 \pm 0.72$ & $0.002 \pm 0.17$ & $0 \pm 0$ & $0.63 \pm 0.48$ \\
1.2 Inactivity & $0.79 \pm 1.05$ & $0.31 \pm 0.68$ & $0.30 \pm 0.47$ & $0.54 \pm 0.66$ \\
1.3 Lentification & $0.79 \pm 1.08$ & $0.51 \pm 0.85$ & $0.57 \pm 0.51$ & $0.85 \pm 0.80$ \\
1.4 Social isolation* & $1.52 \pm 1.40$ & $0.74 \pm 1.22$ & $0.70 \pm 0.88$ & $1.38 \pm 1.50$ \\
2.1 Participation* & $1.10 \pm 1.08$ & $0.31 \pm 0.72$ & $0.27 \pm 0.55$ & $0.85 \pm 0.90$ \\
2.2 Conjugal/affective & $1.00 \pm 0.85$ & $0.96 \pm 1.02$ & $1.00 \pm 1.00$ & $1.22 \pm 0.97$ \\
2.3 Conjugal/sexual & $1.20 \pm 1.15$ & $1.12 \pm 1.05$ & $1.12 \pm 0.99$ & $1.56 \pm 1.13$ \\
2.4 Parental functioning & $0.67 \pm 0.86$ & $0.55 \pm 0.96$ & $0.30 \pm 0.66$ & $0.92 \pm 0.90$ \\
2.5 Sexual & $1.17 \pm 0.94$ & $1.89 \pm 0.93$ & $1.33 \pm 0.82$ & $1.00 \pm 0.82$ \\
2.6 Social contacts & $0.15 \pm 0.61$ & $0.17 \pm 0.62$ & $0.002 \pm 0.29$ & $0.23 \pm 0.60$ \\
2.7 Performance at work* & $1.30 \pm 1.34$ & $0.33 \pm 0.82$ & $0.25 \pm 0.45$ & $1.20 \pm 1.10$ \\
2.8 Interest in work & $1.83 \pm 1.47$ & $1.20 \pm 0.84$ & $0.60 \pm 0.55$ & $1.75 \pm 0.50$ \\
2.9 Information & $1.00 \pm 1.20$ & $0.69 \pm 0.99$ & $1.04 \pm 1.02$ & $0.77 \pm 0.83$ \\
2.10 Emergencies & $0.83 \pm 0.97$ & $0.66 \pm 0.97$ & $0.43 \pm 0.66$ & $1.08 \pm 1.32$ \\
\hline
\end{tabular}

Data are reported as means \pm SD.

${ }^{*} \mathrm{P}<0.05$ for bipolar and double depression patients compared to dysthymic and unipolar patients (ANOVA).

Table 5. Logistic regression analysis between the Global Social Adjustment data and all other variables for which an overall significant association was found.

\begin{tabular}{lccc}
\hline Variables & $P$ & Odds ratio & Confidence interval \\
\hline Unipolar & 0.003 & 0.075 & $0.014-0.043$ \\
Dysthymia & 0.001 & 0.040 & $0.006-0.275$ \\
GARF scale & 0.002 & 0.948 & $0.917-0.981$ \\
\hline
\end{tabular}

GARF $=$ Global Assessment of Relational Functioning Scale. 
cating that unipolar patients presented significantly better results for social adjustment than double depression patients. The odds ratio between double depression and dysthymic patients was 0.043 , indicating that dysthymic patients presented significantly better results for social adjustment than double depression patients.

Family relationship was significantly associated with patient social adjustment (OR $=0.953, \mathrm{CI}=0.916-0.992)$, i.e., the worse the family relationship, the worse the social adjustment.

\section{Discussion}

The present study was conducted on patients treated at a specialized hospital, possibly patients with more severe mood disorders. Evaluations were made knowing the diagnosis and clinical history of the patients, a fact that might also have influenced some of the GSA result.

The 2:1 female/male ratio for mood disorders was higher than previously reported $(14,15)$. Possible explanations include the large number of middle-aged housewives and the functioning hours of the clinic, which may have excluded working men with private medical insurance. Studies have shown that women who work outside the home are less prone to depression and to the use of psychotropic drugs $(16,17)$. Regarding our bipolar patients, a higher predominance of females $(2: 1)$ was also found $(18,19)$. Thus, our data may reflect a local characteristic of the Botucatu population. Overall, this regional sample differed somewhat from those described in other studies (20). Because this sample was drawn from a university hospital with a long history of good medical services, the respondents were older, white, married or living in common law, and not working for pay, and included few men. Hospital hours are not convenient for people who work outside the home. This may be seen as a major limitation of the present study. There- fore, the results cannot be extrapolated to the general population.

Bipolar patients had significantly more frequent hospitalizations throughout life; those with double depression also had been hospitalized more than once during life. Several studies have shown that bipolar patients are hospitalized more than unipolar patients $(21,22)$.

Concerning the lost work days due to disease, the bipolar patients were the most significantly affected, suggesting that, on the basis of missed days of work, patients with bipolar disorder showed more work incapacitation than the others.

Unipolar patients showed the best numerical results for family relationships and double depression patients showed the worst. This agrees with data reported by Leader and Klein (23) who evaluated family relationships for unipolar depression, dysthymia, and double depression. We did not find in the literature any comparative evaluations of family relationships among the four studied groups.

This is the first study in Brazil in which patients with mood disorders treated at a public university hospital were evaluated by a standard instrument for mental illness and social adjustment. In this study, the proportion of patients with some social impairment was very high. None of the patients obtained excellent scores in the overall evaluation of social adjustment and more than $80 \%$ of patients showed some degree of impairment in social adjustment (regular, poor, and severe assessment). More than 30\% showed poor or severe GSA. A study by Judd and Akiskal (24) showed that even the presence of a few depressive symptoms, without being a real syndrome, is an important factor that could predict worse outcome, and that each level of symptom severity is associated with significant psychosocial losses.

In a prospective study of 82 bipolar patients, Gitlin et al. (25) found that social adaptation ranged from reasonable to severe 
impairment in $62 \%$ of them. Kocsis et al. (26) reported that dysthymic patients were impaired in social roles - work, family life, social, and leisure activity time. In studies performed in six European countries, Lépine et al. (27) showed that approximately 2 of 5 patients with depression presented loss of life quality and social and work scope. The present data confirm the findings in the literature regarding social adjustment impairment of patients with mood disorder.

There are few studies comparing social adjustment and different types of mood disorder. We found some studies comparing unipolar and bipolar disorders and others comparing the different forms of depression.

Comparisons between unipolar and bipolar patients concerning social adjustment are still uncertain; some studies have concluded that bipolar patients present worse results for social adjustment than unipolar patients (22). Vocisano et al. (28), on the other hand, found that unipolar patients had worse social adjustment results and social functioning deterioration at younger ages than bipolar patients. The present data confirm those reported in the literature showing that social adjustment is worse in bipolar patients than in unipolar patients.

The results obtained by comparing depressive patients (dysthymic, unipolar, and double depression) are not homogeneous; however, most studies have reported worse social adjustment in double depression (23). Most investigators still suggest that dysthymia and major depression show more similarities than previously thought, and that double depression is most serious with higher social impairment. In the present study, we observed that the most difficult areas for patients in all groups were related to work and sexual relationships (both for married and unmarried patients). Several studies have shown that the different forms of depression lead to a decrease in work and occupational activities, a fact due to a reduction in daily activities $(23,26)$. Goering et al. (29) reported high dissatisfaction of depressed women with sexual relationships. The present data confirm these findings and suggest that this is the area most affected by mood disorders.

In the multivariate analysis (logistic regression), the most significant predictive variables of social adjustment were diagnosis and family relationship. Bipolar disorder and double depression were significantly worse than unipolar and dysthymic disorders for social adjustment. In the present study, family relationships were significantly associated with social adjustment, in agreement with most literature reports $(21,30)$.

The high frequency and intensity of social incapacitation in mood disorder patients indicate the need for more effective interventions. Bipolar and double depression patients were socially maladjusted especially in terms of personal care, social isolation, domestic participation, and work performance. The mood quality of the family environment is a significant predictor of the course of mood disorders. We suggest a psychoeducational process focused on the characteristics of mood disorders (course, prognosis, treatment), which could benefit both patient and family by reducing stress and improving functioning between episodes.

\section{Acknowledgments}

The authors thank Dr. Ivete Dalben for assistance with the statistical program for data analysis. 


\section{References}

1. Winokur G, Coryell W, Akiskal HS, Endicott J, Keller M \& Mueller T (1994). Manic-depressive (bipolar) disorder: the course in light of a prospective ten-year follow-up of 131 patients. Acta Psychiatrica Scandinavica, 89: 102-110.

2. Klerman GL \& Weissman MM (1992). The course, morbidity and costs of depression. Archives of General Psychiatry, 49: 831-834.

3. Beiser M, Bean G, Erikson D, Zhang J, lacono WG \& Rector NA (1994). Biological and psychosocial predictors of job performance following a first episode of psychosis. American Journal of Psychiatry, 51: 857-863.

4. Martin JK, Blum TC, Black SRH \& Roman PM (1996). Subclinical depression and performance at work. Social Psychiatry and Psychiatric Epidemiology, 31: 3-9.

5. Vaughn CE \& Leff JP (1976). The influence of family and social factors on the course of psychiatric illness. British Journal of Psychiatry, 129: 125-137.

6. Organização Mundial da Saúde (1993). Classificação de Transtornos Mentais e de Comportamento. CID-10. Artes Médicas, Porto Alegre, RS, Brazil.

7. Word Health Organization (1988). Psychiatric Disability Assessment Schedule. WHO/DAS, Geneva, Switzerland.

8. Chaves AC, Sarin LM \& Mari JJ (1990). Escala de avaliação de incapacitação psiquiátrica (DAS). Escola Paulista de Medicina, São Paulo, SP, Brazil.

9. Menezes PR \& Scazufca M (1993). Estudo de confiabilidade da versão em português da Escala de Avaliação da Incapacidade Psiquiátrica (WHO/DAS). Revista da Associação Brasileira de Psiquiatria-Asociación Psiquiátrica de la América Latina, 15: 65-67.

10. American Psychiatric Association (1994). Diagnostic and Statistical Manual of Mental Disorders. 4th edn. American Psychiatric Association, Washington, DC, USA.

11. SPSS (1996). SPSS Advanced Statistics TM. Software version 7.07.5, Chicago, IL, USA.

12. Kahn HÁ \& Sempos CT (1989). Statistical Methods in Epidemiology. Oxford University Press, New York.

13. Siegel S (1975). Estatística Não Paramétrica. McGraw-Hill do Brasil, São Paulo, SP, Brazil.

14. Paykel ES (1991). Depression in women. British Journal of Psychiatry, 158: 22-29.

15. Coryell W, Endicott J \& Keller M (1992). Major depression in a nonclinical sample. Archives of General Psychiatry, 49: 117-125.

16. Rocha-Coutinho ML (1994). Tecendo por trás dos Panos. A Mulher Brasileira nas Relações Familiares. Rocco, Rio de Janeiro, RJ, Brazil.

17. Madrigal E (1993). Patrones de consumo y dependencia del alcohol y de substancias psicoactivas en la mujer. In: Gómez E (Editor), Género, Mujer Y Salud en Las Americas. Organização Panameri- cana de Saúde, 163-177

18. Almeida Filho N, Mari JJ, Coutinho E, França JF, Fernando JG, Andreoli SB \& Busnello EA (1992). Estudo multicêntrico em áreas urbanas brasileiras (Brasília, São Paulo, Porto Alegre). Revista da Associação Brasileira de Psiquiatria-Asociación Psiquiátrica de la América Latina, 14: 93-104.

19. Kessler RC, McGonagle KA \& Zhao S (1994). Lifetime and 12-month prevalence of DSM-III-R psychiatric disorders in the United States. Archives of General Psychiatry, 51: 8-19.

20. Kerr-Corrêa F \& Corat S (1995). Depressões unipolares, bipolares e distimia: características de evolução clínica e antecedentes em 74 pacientes. Anais da XIX Jornada Científica da Associação dos Docentes, UNESP, Botucatu, SP, Brazil, October 15-18.

21. Winokur G, Coryell W, Keller M, Endicott J \& Akiskal HS (1993). A prospective follow-up of patients with bipolar and primary unipolar affective disorder. Archives of General Psychiatry, 50: 457-465.

22. Goldberg JF, Harrow M \& Grossman LS (1995). Recurrent affective syndromes in bipolar and unipolar mood disorders at follow-up. British Journal of Psychiatry, 66: 382-385.

23. Leader JB \& Klein DN (1996). Social adjustment in dysthymia, double depression and episodic major depression. Journal of Affective Disorders, 37: 91-101.

24. Judd LL \& Akiskal HS (2000). Delineating the longitudinal structure of depressive illness: beyond clinical subtypes and duration thresholds. Pharmacopsychiatry, 33: 3-7.

25. Gitlin MJ, Swendsen J \& Heller JL (1995). Relapse and impairment in bipolar disorder. American Journal of Psychiatry, 152: 1635-1640.

26. Kocsis JH, Zisook S, Davidson J, Shelton R, Yonkers K, Hellerstein DJ, Rosenbaum J \& Halbreich U (1997). Double-blind comparison of sertraline, imipramine and placebo in the treatment of dysthymia: psychosocial outcomes. American Journal of Psychiatry, 154: 390395.

27. Lépine JP, Gaspar M, Mendlewicz J \& Tylee A (1997). Depression in the community: the first pan-European study DEPRES (Depression Research in European Society). International Clinical Psychopharmacology, 12: 12-19.

28. Vocisano C, Klein DN, Keefe RSE, Dienst ER \& Kincaid MM (1996). Demographics, family history, premorbid functioning, development characteristics, and course of patients with deteriorated affective disorder. American Journal of Psychiatry, 153: 248-255.

29. Goering PN, Lance WJ \& Freeman JJ (1992). Marital support and recovery from depression. British Journal of Psychiatry, 160: 76-82.

30. Lish JD, Dime-Meenan S, Whybrow PC, Price RA \& Huschfeld RMA (1994). The National Depressive and Manic-Depressive Association (DMDA) survey of bipolar members. Journal of Affective Disorders, 31: 281-294. 